ISSN 0103-9954

\title{
EFEITOS DOS ESTRESSES HIDRICO E SALINO E DA AÇÃO DE GIBERELINA EM SEMENTES DE Senna spectabilis
}

\section{EFFECTS OF WATER AND SALT STRESS AND THE GIBBERELLIN ACTION IN Senna spectabilis SEEDS}

\author{
Helma Jeller ${ }^{1}$ Sonia Cristina Juliano Gualtierres de Andrade Perez ${ }^{2}$
}

\section{RESUMO}

Senna spectabilis (DC.) Irwin et Barn. variedade excelsa (Schrad.) Irwin et Barn. é uma leguminosa de porte arbóreo indicada para paisagismo, arborização urbana e plantios em áreas degradadas recomendadas para preservação permanente. Na arborização ou em áreas degradadas essas plantas ficam sujeitas ao estresse hídrico e/ou salino. Assim foram estudados aspectos relativos aos efeitos desses estresses simulados e a ação de fitorregulador em sementes sob tais estresses. As sementes foram colocadas em placas de Petri sobre papel de filtro umedecido com Captan (2\%) ou solução-teste e incubadas sob $27^{\circ} \mathrm{C}$. As soluções-teste foram PEG 6000 a 0,$0 ;-0,2 ;-0,4 ;-0,6 ;-0,7$ e $-0,8 \mathrm{MPa}$ e $\mathrm{NaCl}$ a 0,$0 ;-0,2 ;-0,4 ;-0,6 ;-0,8 ;-1,0 ;-1,2 ;-1,4 ;-1,5 ;-1,6$ e -1,7MPa com ou sem a adição de $\mathrm{GA}_{3}$. As sementes de Senna spectabilis sob estresse hídrico induzido com PEG 6000 apresentaram limite máximo de germinabilidade a $-0,7 \mathrm{MPa}$, não sendo considerado um limite elevado de tolerância, em comparação com outras espécies lenhosas. Com relação ao efeito do estresse salino, a diminuição do potencial osmótico das soluções de $\mathrm{NaCl}$ levou a um decréscimo no sincronismo, na velocidade e germinabilidade, com germinação totalmente suprimida a -1,6MPa. A adição de 40ppm de ácido giberélico atenuou parcialmente os efeitos dos estresses hídrico e salino.

Palavras-chave: Cassia excelsa, Senna spectabilis, germinação, estresse, giberelina.

\begin{abstract}
Senna spectabilis (DC.) Irwin et Barn. variedade excelsa (Schrad.) Irwin et Barn. is a leguminosae woody species of low frequency in cerrado and caatinga of the Brazilian northeast. It is used in landscaping designs due to it's natural beauty, streets arborization and in reflorestation of degraded areas. The aim of this work was to extend the knowledge about the biology of this species and to study the effects of water and salt stress and gibberellins on seed germination. Four replications of 50 seeds were used for each treatment and germination was carried out in $9 \mathrm{~cm}$ Petri lived with filter paper moistened with test-solution. Senna espectabilis seeds did not present a wide tolerance to water stress and the germination was supressed at $-0,7 \mathrm{MPa}$. The reduction of $\mathrm{NaCl}$

1. Bióloga, Pós-Graduada, Departamento de Botânica, Universidade Federal de São Carlos, Caixa Postal 676, CEP 13565-905, São Carlos (SP). vsouza@ @in.ufms.br

2. Bióloga, Prof adjunta do Departamento de Botânica, Universidade Federal de São Carlos, Caixa Postal 676, CEP 13565-905, São Carlos (SP). dscp@ power.ufscar.br
\end{abstract}


osmotic potential decreased germination and synchrony of the process. The maximal tolerance limit was at $-1,6 \mathrm{MPa}$, when germination was totally inhibited. The addition of gibberellic acid reduced partially the effects of water and salt stress.

Key words: seeds, Cassia excelsa, Senna espectabilis, stress, gibberellin.

\section{INTRODUÇÃO}

Estudos sobre relações hídricas são importantes para o conhecimento da biologia das sementes. A habilidade de tolerar a dessecação que as sementes ortodoxas apresentam, podendo sobreviver durante longos períodos sob condições adversas, tem sido o mecanismo adaptativo que permite a distribuição de plantas em climas hostis (BRADFORD, 1995).

Sob baixos níveis de umidade no meio germinativo, é comum o desenvolvimento de mecanismos protetores contra a dessecação ou para evitar a parada do desenvolvimento (BEWLEY \& OLIVER, 1992), porém um estresse hídrico severo resulta em desequilíbrio metabólico (BLACKMAN et al.., 1992). Mesmo assim, a respiração pode continuar nos tecidos com potenciais abaixo de -1,10MPa, mantendo o organismo vivo com um metabolismo baixo (VERTUCCI, 1989). Além da seca, a salinidade é um problema cada vez maior para a agricultura, sendo que o aumento desta última prejudica a vegetação nativa em consequiência dos efeitos tóxicos e osmóticos dos sais na germinação e crescimento das plantas (GHASSEMY et al.., 1995).

É sabido que, em condições de estresse há um desequilíbrio no balanço hormonal. Desta forma, a falta de germinação pode ser por causa da presença de inibidor(es) ativo(s) e/ou deficiência de promotor(es) essencial(ais) nessas sementes. Em tais condições, a adição de um fitorregulador pode induzir ou estimular a germinação (DAVIES,1994). As giberelinas constituem uma classe de substâncias reguladoras de crescimento, como por elongação, e que controla a hidrólise de reservas, entre outras funções. Dentre as várias giberelinas, o $\mathrm{GA}_{3}$ está disponível comercialmente e tem sido muito usado em sistemas biológicos (ARTECA, 1996).

Ao processo intenso e contínuo de exploração e devastação de matas nativas, que resultam no extermínio de várias espécies com potencial para múltiplos usos, soma-se a carência de informações sobre as espécies nativas tropicais, o que dificulta a adoção de práticas conservacionistas ou de recuperação de áreas degradadas (CARPI et al., 1996).

Senna spectabilis (DC.) Irwin et Barn. variedade excelsa (Schrad.) Irwin et Barn. é uma espécie de porte arbóreo encontrada nos cerrados e nas caatingas do nordeste brasileiro (BRAGA, 1982). Floresce amplamente durante todo o verão e por seu efeito ornamental pode ser empregada para paisagismo em geral e, em consequiência do seu pequeno porte, é indicada para arborização urbana, podendo ser também destinada para recomposição de áreas degradadas e indicada para preservação permanente. $\mathrm{Na}$ arborização ou em áreas degradadas, essas plantas ficam sujeitas ao estresse hídrico e/ou salino. Desse modo, estudou-se, neste trabalho, os efeitos do estresse hídrico e salino, e a ação de fitoregulador no processo germinativo das sementes de Senna spectabilis. 


\section{MATERIAL E MÉTODO}

As sementes de Senna spectabilis utilizadas foram inicialmente selecionadas a fim de se obter uniformidade quanto ao aspecto de cor, tamanho e estado de conservação. Antes dos testes, as sementes foram contadas e submetidas aos procedimentos para a quebra de dormência com a escarificação em ácido sulfúrico concentrado por 25 minutos (JELLER \& PEREZ, 1999). Utilizaram-se 4 repetições de 50 sementes distribuídas em placas de Petri de $9 \mathrm{~cm}$ de diâmetro contendo internamente duas folhas de papel de filtro umedecidas com água destilada ou solução teste, acrescidas com o fungicida Captan (0,2\%), e colocadas em incubadora (Tipo B.O.D.) a $27^{\circ} \mathrm{C}$ (JELLER \& PEREZ, 1999). As sementes que apresentaram comprimento radicular maior ou igual a $2 \mathrm{~mm}$ e curvatura geotrópica positiva (DURAN \& TORTOSA, 1985) foram contadas e retiradas das placas diariamente (BRASIL, 1992). Os experimentos foram considerados finalizados, quando todas as sementes já haviam germinado, ou quando as remanescentes nas placas apresentavam sinais de deterioração. A fim de simular um déficit hídrico e encontrar o limite máximo de tolerância à seca, foi utilizado polietilenoglicol (PEG 6000 - "LABSYNTH"), pelo fato deste composto ser quimicamente inerte e não-tóxico (DELACHIAVE, 1984) nos seguintes potenciais osmóticos: 0,0; 0,$2 ;-0,4 ;-0,6 ;-0,7$ e $-0,8 \mathrm{MPa}$, preparadas de acordo com a tabela citada por VILLELA et al. (1991). Para simular um estresse salino e determinar o limite máximo de tolerância, utilizaram-se soluções de $\mathrm{NaCl}(\mathrm{P} . \mathrm{M} .=58,44)$ nos seguintes potenciais osmóticos: 0,$0 ;-0,2 ;-0,4 ;-0,6 ;-0,8 ;-1,0$; $-1,2 ;-1,4 ;-1,5 ;-1,6$ e -1,7MPa. As concentrações dos sais, para cada potencial osmótico, foram obtidas com base na equação de J.H.van't Hoff, citada por SALISBURY \& ROSS (1992). O ácido giberélico $\left(\mathrm{GA}_{3}\right)$ foi adicionado na concentração de 40ppm nas soluções de $-0,6 ;-0,7$ e $-0,8 \mathrm{MPa}$ de PEG, e nas soluções de $-0,8 ;-1,0 ;-1,2 ;-1,4 ;-1,5$ e $-1,6 \mathrm{MPa}$ de cloreto de sódio, sendo as que proporcionaram diminuições significativas na germinabilidade e velocidade de germinação. Para cálculo da porcentagem e velocidade de germinação foram utilizadas fórmulas citadas por LABOURIAU \& VALADARES (1976) e entropia informacional (sincronização) por LABOURIAU (1978). O delineamento estatístico utilizado foi inteiramente casualizado. As médias foram

transformados em Arco seno $\sqrt{\%} / 100$, e submetidos à analise de variância (SPIEGEL, 1978). Para contraste das médias utilizou-se o teste de Tukey (0,05\%) (COCHRAN \& COX, 1957).

\section{RESULTADOS E DISCUSSÃO}

\section{Efeito do estresse hídrico}

As sementes de Senna spectabilis, submetidas ao estresse hídrico, apresentaram um decréscimo na germinabilidade e na velocidade de germinação à medida que o potencial osmótico do meio se tornou mais negativo. Os valores de germinabilidade diferiram estatisticamente do controle $(91,5 \%)$ a $-0,6 \mathrm{MPa}(27 \%)$, indicando sensibilidade das sementes ao estresse. A menor germinação foi observada em -0,7MPa (16,2\%), e ausência de germinação em -0,8MPa (Figura 1).

Resultados semelhantes foram obtidos por TAMBELINI \& PEREZ (1998) e ZPEVAK (1994) com ausência de germinação em Stryphnodendrom polyphyllum e Dimorphandra mollis, 
respectivamente, a 0,7MPa. CHOINSKI \& TUOHY (1993) verificaram também a redução da germinação em leguminosas da savana africana (Combretum apiculatum, Colophospermum mopane, Acacia karroo e Acacia tortilis) a partir de -0,3MPa. Já PEREZ \& NASSIF (1995) verificaram um limite mais elevado em algarobeira (-1,4 e -1,6MPa).

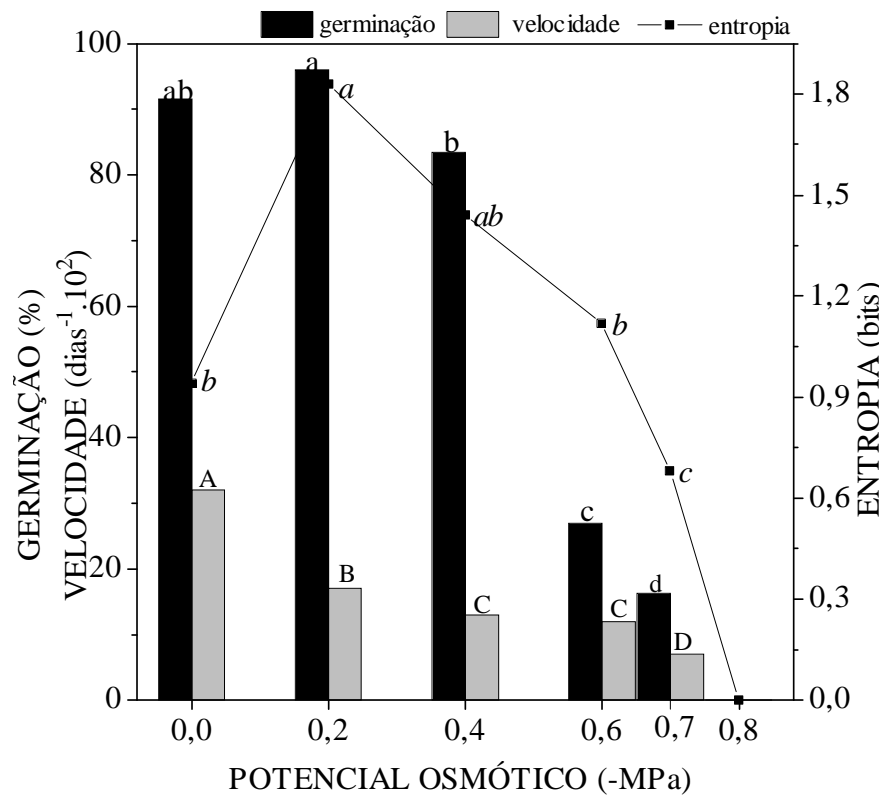

FIGURA 1: Efeitos das soluções de PEG 6000 com diferentes potenciais. osmóticos em porcentagem de germinação, velocidade e entropia informacional de sementes de Senna spectabilis ao longo do tempo de incubação isotérmica a $27^{\circ} \mathrm{C}$.

Esse comportamento de redução da germinabilidade, quando o potencial osmótico se torna mais negativo, é em razão do aumento no tempo correspondente à fase dois do processo de embebição, segundo o padrão trifásico proposto por BEWLEY \& BLACK (1994) em que a fase um é caracterizada por um uma rápida absorção de água. $\mathrm{Na}$ fase dois, constata-se pouca ou nenhuma absorção de água e a fase três com intensa absorção de água e protrusão da raiz primária. Dessa forma, na fase dois ocorreria uma elevação na concentração do fitoregulador ácido abscísico (ABA) nas sementes com uma conseqüente inibição do alongamento celular (EIRA, 1988) e redução da germinação.

A intensidade da resposta ao estresse hídrico é variável entre as sementes de diferentes espécies, e o que é sentido como um estresse depende não somente da constituição genética mas, também da condição fisiológica da semente (HEYDECKER, 1977).

A velocidade de germinação foi ainda mais suscetível ao estresse hídrico do que a germinabilidade, com reduções significativas em relação ao controle já à 0,2MPa (Figura 1). Esses dados concordam com as informações de HEYDECKER (1977), de que o aumento do estresse ambiental, em geral, leva inicialmente a um decréscimo na velocidade de germinação e só posteriormente vem afetar a germinabilidade das sementes.

Resultados análogos foram obtidos por FANTI \& PEREZ (1998) na germinação de 
sementes de Adenanthera pavonina com a porcentagem e a velocidade muito afetadas com a diminuição do potencial hídrico induzido por PEG, a -0,4MPa, em comparação com NASSIF \& PEREZ (1997) que só observaram reduções significativas da porcentagem e velocidade de Pterogyne nitens em potenciais -1,0MPa de PEG.

Os valores de entropia informacional (sincronismo), para Senna spectabilis, apresentaram uma variação significativa em relação ao controle à $-0,2 \mathrm{MPa}$, em que foi observado valor máximo (Figura 1). Com base nesse potencial, os valores decresceram com a diminuição do potencial osmótico externo, mantendo-se estatisticamente igual ao controle, em conseqüência de um pequeno número de sementes que germinaram ao longo do tempo de incubação. De acordo com Moore \& Kid, citado por BORGES et al. (1991), as variações, na germinabilidade, obtidas em diferentes potenciais osmóticos entre as espécies, refletem a disponibilidade de umidade no local de origem das sementes, indicando diferenciação de espécie em ecótipos distintos.

\section{Efeito do Estresse Salino}

Houve uma redução na germinabilidade das sementes de Senna spectabilis à medida que o potencial osmótico das soluções de $\mathrm{NaCl}$ tornou-se mais negativo (Figura 2). Além do atraso no processo germinativo, houve diminuição da sincronização, ou seja, um aumento da entropia informacional, que mostra uma redução no grau de organização do sistema, levando a uma distribuição mais esparsa no tempo de germinação dessas sementes. Atribui-se a esse tipo de distribuição, um caráter adaptativo, como uma compensação às condições desfavoráveis do meio, por uma maior distribuição no espaço.

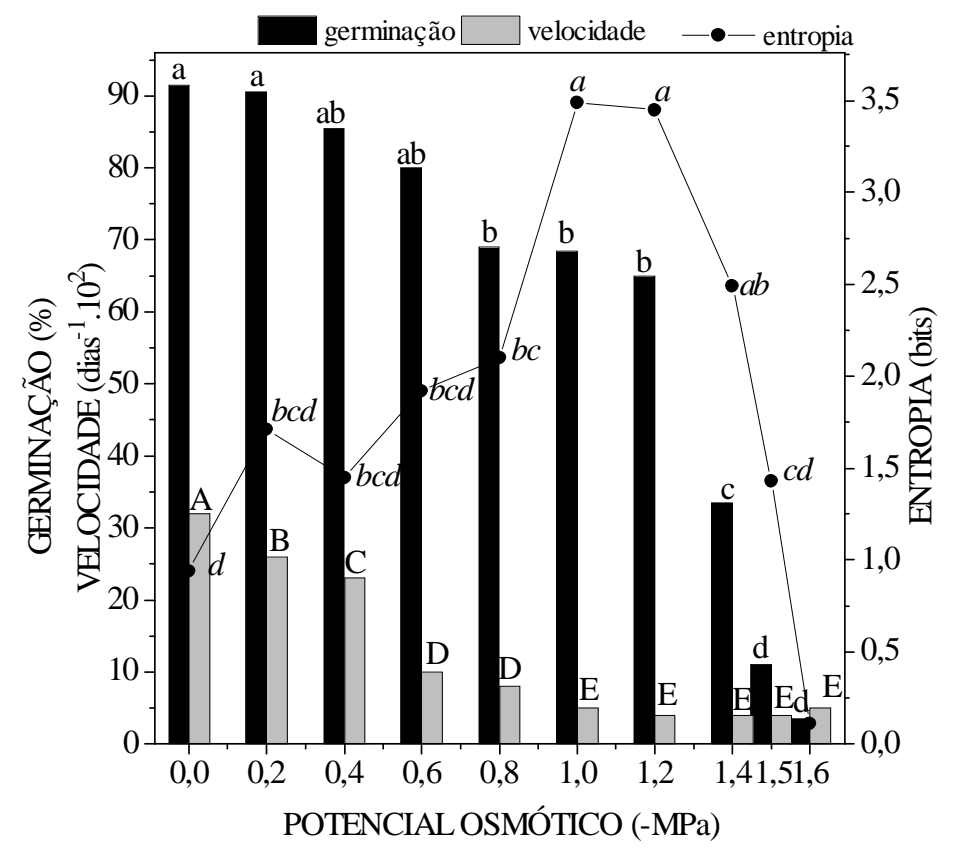

FIGURA 2: Influência das soluções de salinas $(\mathrm{NaCl})$ com diferentes potenciais osmóticos em porcentagem de germinação, velocidade e entropia informacional de sementes de Senna spectabilis ao longo do tempo de incubação isotérmica a $27^{\circ} \mathrm{C}$. 
Analisando os valores de porcentagem de germinação, observou-se a existência de diferenças significativas entre o controle $(91,5 \%)$ e soluções com potencial osmótico de $-0,8 \mathrm{MPa}(69,0 \%)$, sendo que o menor valor foi encontrado em -1,6MPa $(3,5 \%)$ e ausência total de germinação foi registrada a $-1,7 \mathrm{MPa}$ (Figura 2). Nos potenciais osmóticos mais negativos, as sementes apresentavam o tegumento escurecido e envolvido por um exsudato de aspecto gelatinoso, que pode ser uma tentativa de reduzir o contato com as condições estressantes, o que pode ser interpretado como uma adaptação da espécie ao estresse, o que asseguraria a sua sobrevivência, nessas condições por algum tempo.

Comportamento semelhante foi observado em sementes de Copaifera langsdorffii por JELLER \& PEREZ (1997) com limite máximo de tolerância a -1,6MPa. Em Prosopis juliflora foi observada, por PEREZ \& TAMBELINI (1995), significativa redução da germinabilidade com base em -0,6MPa. A natureza dessa inibição da germinação, causada pelo estresse salino, é discutível. O alto conteúdo de sais no solo, especialmente o cloreto de sódio, pode inibir a germinação, inicialmente em face de efeitos osmóticos e, em alguns casos, por efeitos tóxicos cuja magnitude depende do grau de tolerância e/ou resistência à salinidade, os quais dependem não só da espécie utilizada como também do tipo de sal (FERREIRA \& REBOUÇAS, 1992).

O estresse salino interferiu mais intensamente na velocidade do que na germinabilidade, pois as diferenças significativas, em relação ao controle, começaram a ser notadas com o uso em potencial osmótico igual a $-0,2 \mathrm{MPa}$. A velocidade continuou diminuindo significativamente até 1,2MPa. Após esse valor de potencial, não foram constatadas diferenças no tempo de germinação, devido às poucas sementes que germinaram no início do teste, mascarando desta forma, a resposta do efeito inibitório desses potenciais sobre a velocidade de germinação (Figura 2). A velocidade de germinação de sementes de Leucaena leucocephala (CAVALCANTE \& PEREZ,1995) e Adenanthera pavonina (FANTI \& PEREZ, 1998) também diminuiu com o aumento da concentração de $\mathrm{NaCl}$ do meio germinativo, apresentando diferenças significativas entre o controle $(0,0 \mathrm{MPa})$ e os demais potenciais osmóticos testados.

As sementes de Senna spectabilis apresentaram uma diminuição na sincronização do processo germinativo à medida que os potenciais osmóticos das soluções salinas foram reduzidos. A entropia informacional diferenciou-se significativamente do controle no potencial de $-0,8 \mathrm{MPa}$, atingindo seu valor máximo a $-1,0 \mathrm{MPa}$ que não foi significativamente diferente dos potenciais inferiores. O decréscimo do valor verificado nesses potenciais, deve-se ao fato da germinação antecipada de poucas sementes, as mais vigorosas (Figura 2).

Geralmente, tanto halófilas como glicófilas respondem de maneira semelhante ao estresse salino, sendo a porcentagem e a velocidade de germinação inversamente proporcionais ao aumento da salinidade, variando apenas o limite de tolerância ao sal. Halófilas altamente tolerantes podem germinar em meio com até $8 \%$ de $\mathrm{NaCl}$ (UNGAR, 1978), entretanto, as halófilas pouco tolerantes têm sua germinação inibida em meio com concentrações superiores a 1,5\% de $\mathrm{NaCl}$. Já a maioria das glicófilas não germina em meio com concentrações superiores a 1,5\% de $\mathrm{NaCl}$. Outra característica importante das halófilas, que as distingue das glicófilas, é a sua habilidade de permanecer dormentes sem-perda de viabilidade em altas concentrações salinas e depois germinarem prontamente quando a concentração de $\mathrm{NaCl}$ do meio é reduzida, caracterizando uma resposta de recuperação (UNGAR, 
1978). Provavelmente, as glicófilas não apresentam essa resposta de recuperação, uma vez que o $\mathrm{NaCl}$ produz efeito tóxico, além do osmótico. Porém, nas halófilas o efeito dos sais é principalmente osmótico e, nessa categoria de plantas, a resposta de recuperação está sempre presente (WILLIAN \& UNGAR, 1972).

Neste estudo, Senna spectabilis pode ser incluída entre as glicófilas pouco tolerantes ao sal, pois não apresentam um limite elevado de tolerância $(-1,6 \mathrm{MPa})$, e não apresentam resposta de recuperação nos potenciais osmóticos mais negativos, confirmando os resultados apresentados por CAVALCANTE \& PEREZ (1995) com sementes de Leucaena leucocephala com limite em -1,3MPa, por FANTI \& PEREZ (1996) com Bauhinia forficata com limite entre -1,2 e -1,3MPa e por FANTI \& PEREZ (1998) com sementes de Adenanthera pavonina com limite em -1,4MPa, todas consideradas glicófilas pouco tolerantes ao sal.

Para sementes de Senna spectabilis, o PEG causou maior efeito na germinabilidade do que $\mathrm{NaCl}$ (Figura 3). Essa resposta pode ser atribuída à tolerância própria da espécie ao $\mathrm{NaCl}$ (UNGAR, 1978). Além disso, embora o PEG não seja absorvido em virtude do seu alto peso molecular, as soluções preparadas com tal substância podem apresentar alta viscosidade, que somada à baixa difusão de $\mathrm{O}_{2}$, podem comprometer a disponibilidade de oxigênio para as sementes, durante o processo germinativo (BRACCINI et al.,1996).

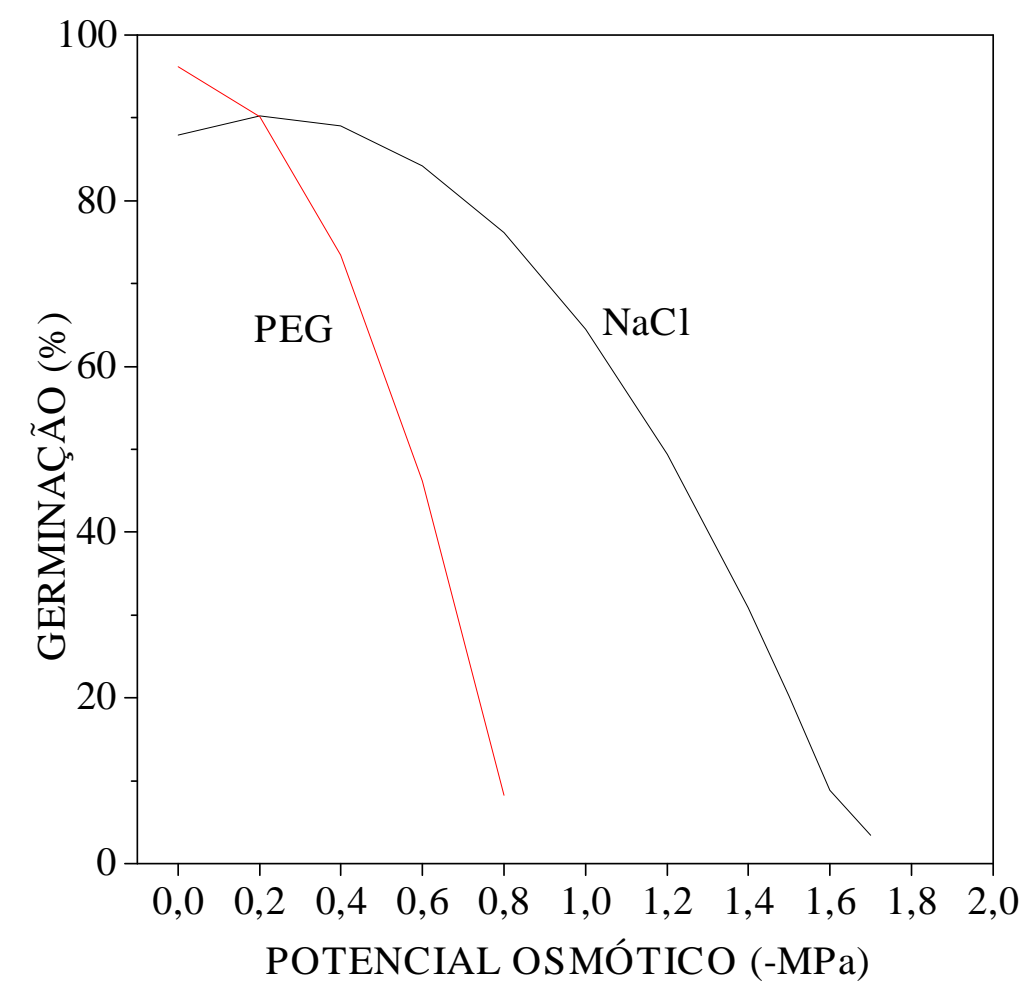

FIGURA 3: Influência de diferentes potenciais osmóticos das soluções de $\mathrm{NaCl}$ e polietilenoglicol (PEG 6000) na porcentagem de germinação de Senna spectabilis após 30 dias de incubação a $27^{\circ} \mathrm{C}$. 
Resultados semelhantes ao trabalho presente foram obtidos por NASSIF \& PEREZ (1997) e FANTI \& PEREZ (1998) em sementes de Pterogyne nitens e Adenanthera pavonina, respectivamente. BRACCINI et al. (1996), trabalhando com sementes de soja, também verificaram redução na porcentagem de germinação, à medida que os potenciais osmóticos das soluções de $\mathrm{NaCl}$, manitol e PEG tornaram-se mais negativos e verificaram também que o PEG foi o agente osmótico que promoveu maior decréscimo na germinação. Esse resultado foi atribuído às propriedades do PEG anteriormente relatados. Neste estudo o PEG afetou mais a germinação, e o $\mathrm{NaCl}$ afetou mais a velocidade de germinação das sementes de Senna spectabilis.

\section{Atenuação do estresse hídrico e salino com adição de giberelina}

A adição de $40 \mathrm{ppm}$ de $\mathrm{GA}_{3}$ provocou diferenças significativas na porcentagem de germinação das sementes de Senna spectabilis, mostrando-se eficaz na atenuação do estresse hídrico induzido pelas soluções de PEG. No potencial osmótico de -0,8MPa não ocorreu a germinação, porém com a adição de $\mathrm{GA}_{3}$, verificou-se um aumento relativo na porcentagem de germinação, levando a ampliação do limite máximo de tolerância ao estresse hídrico (Tabelas 1 e 2).

TABELA 1: Valores médios de germinabilidade de sementes de Senna spectabilis submetidas a soluções de PEG 6000 com diferentes potenciais osmóticos e à ação do ácido giberélico (40ppm).

\begin{tabular}{|c|c|c|c|c|c|c|}
\hline \multirow{2}{*}{$\begin{array}{c}\text { Potencial Osmótico } \\
(-\mathrm{MPa})\end{array}$} & & 0,6 & & 0,7 & & 0,8 \\
\hline & \multicolumn{6}{|c|}{ Germinação } \\
\hline Tratamentos & $\%$ & $(\operatorname{arcsen} \sqrt{\%})$ & $\%$ & $(\operatorname{arcsen} \sqrt{\%})$ & $\%$ & $(\operatorname{arcsen} \sqrt{\%})$ \\
\hline sem $\mathrm{GA}_{3}$ & 27,0 & $31,28 \mathrm{a}$ & 16,2 & $15,21 a$ & 0,0 & 0,0 \\
\hline $\operatorname{com~GA} 3$ & 72,0 & $58,68 \mathrm{~b}$ & 70,0 & $56,87 \mathrm{~b}$ & 40,5 & 39,43 \\
\hline
\end{tabular}

Em que: médias seguidas pela mesma letra na coluna não diferem entre si pelo teste Tukey pelo nível de probabilidade adotado $(\mathrm{p}<0,05)$.

Segundo BEWLEY \& BLACK (1994), o ácido giberélico é um ativador enzimático endógeno, portanto, promotor da germinação, aumentando a porcentagem e a velocidade de germinação. As giberelinas atuam na expressão gênica, ativação e síntese de várias enzimas, dentre elas, enzimas que hidrolisam e mobilizam reservas dos tecidos. Nesse sentido, vários autores conseguiram aumentar o desenpenho germinativo de muitas espécies com a utilização de $\mathrm{GA}_{3}$ em sementes de Cupressus sempervirens (JOHN \& PAUL, 1994) e em Fagus silvatica (NICOLAS et al.., 1996). Também KITCHEN \& MEYER (1991), observaram um estímulo à germinação em 27 espécies de Penstemon sp., e CASTRO et al.. (1999) em sementes de Guarea guidonea tratadas com $\mathrm{GA}_{3}$.

A adição do $\mathrm{GA}_{3}$ causou estímulo significativo à germinabilidade das sementes sob estresse salino nos potenciais $-0,8 \mathrm{MPa}$, em que na ausência desse fitoregulador, não ocorreu a germinação, indicando, dessa forma, sua eficácia na atenuação do estresse hídrico induzido pelas soluções de PEG, conduzindo assim a uma ampliação do limite máximo de tolerância ao estresse hídrico. Porém, nos demais potenciais, a resposta foi estatisticamente igual ao das soluções salinas sem- fitoregulador, indicando que, provavelmente, os processos metabólicos essenciais das sementes 
podem ter sido intensamente afetados, impedindo a germinação dessas sementes (KHAN \& UNGAR, 1985).

TABELA 2: Valores médios de germinabilidade de sementes de Senna spectabilis submetidas a soluções salinas $(\mathrm{NaCl})$ em diferentes potenciais osmóticos e à ação do ácido giberélico (40ppm).

\begin{tabular}{|c|c|c|c|}
\hline \multirow{2}{*}{$\begin{array}{l}\text { Potencial Osmótico } \\
\text { (-MPa) }\end{array}$} & \multirow[t]{2}{*}{ Tratamentos } & \multicolumn{2}{|c|}{ Germinabilidade } \\
\hline & & $\%$ & $(\operatorname{arcsen} \sqrt{\%})$ \\
\hline \multirow[t]{2}{*}{0,8} & sem $\mathrm{GA}_{3}$ & 69,1 & $56,17 \mathrm{a}$ \\
\hline & com $\mathrm{GA}_{3}$ & 85,5 & $67,69 b$ \\
\hline \multirow[t]{2}{*}{1,0} & sem $\mathrm{GA}_{3}$ & 68,5 & $56,08 \mathrm{a}$ \\
\hline & $\operatorname{com~GA} 3$ & 75,5 & $62,51 \mathrm{a}$ \\
\hline \multirow[t]{2}{*}{1,2} & sem $\mathrm{GA}_{3}$ & 65,0 & $54,36 \mathrm{a}$ \\
\hline & $\operatorname{com} \mathrm{GA}_{3}$ & 63,0 & $52,73 a$ \\
\hline \multirow[t]{2}{*}{1,4} & sem $\mathrm{GA}_{3}$ & 33,5 & $34,72 \mathrm{a}$ \\
\hline & $\operatorname{com~} \mathrm{GA}_{3}$ & 41,0 & $39,75 \mathrm{a}$ \\
\hline \multirow[t]{2}{*}{1,5} & sem $\mathrm{GA}_{3}$ & 11,0 & $16,65 \mathrm{a}$ \\
\hline & com $\mathrm{GA}_{3}$ & 5,0 & $12,02 \mathrm{a}$ \\
\hline \multirow[t]{2}{*}{1,6} & sem $\mathrm{GA}_{3}$ & 3,5 & $10,49 \mathrm{a}$ \\
\hline & $\operatorname{com} \mathrm{GA}_{3}$ & 3,0 & $9,83 \mathrm{a}$ \\
\hline \multirow[t]{2}{*}{1,7} & sem $\mathrm{GA}_{3}$ & \multirow{2}{*}{\multicolumn{2}{|c|}{$\begin{array}{l}\text { não ocorreu a germinação } \\
\text { não ocorreu a germinação }\end{array}$}} \\
\hline & $\operatorname{com} \mathrm{GA}_{3}$ & & \\
\hline
\end{tabular}

Em que: médias seguidas pela mesma letra na linha não diferem entre si, pelo teste Tukey pelo nível de probabilidade adotado $(\mathrm{p}<0,05)$.

\section{CONCLUSÕES}

Pode-se concluir sobre as sementes de Senna spectabilis que:

É uma espécie pouco tolerante ao estresse hídrico com limite máximo de germinabilidade a $-0,7 \mathrm{Mpa}$.

É uma glicófila pouco tolerante ao sal, com limite máximo de tolerância ao $\mathrm{NaCl}$ entre $-1,6$ e $-1,7 \mathrm{Mpa}$.

Apresenta sensibilidade maior ao estresse hídrico de que ao estresse salino.

O ácido giberélico aumenta o potencial de germinação das sementes sob estresse hídrico ou salino. 


\section{REFERÊNCIAS BIBLIOGRÁFICAS}

ARTECA, R.D. Plant growth substances principles and applications. New York, Chapman \& Mall, 1996. $332 p$.

BEWLEY, J.D.; BLACK, M. Seeds: physiology of development and germination. New York: Plenum Press, 1994. 445p.

BEWLEY, J.D.; OLIVER, M.J. Desiccation tolerance in vegetative plant tissues and seeds: protein synthesis in relations to dessecations and a potential role for protection and repair mechanisms. In: OSMOND, C,D.; SOMERO, G. \& BOLIS, C.L. (eds). Water and life: a comparative analysis of water relationships at the organismic, celular and molecular levels. Berlin: Spring Verlag, 1992. p.141- 160.

BLACKMAN, S.A.; OBENDORF, R.L.; LEOPOLD, A.C. Maturation proteins and sugars in desiccation tolerance of developing soybean seeds. Plant Physiology, Bethesda, v.100, p.225-230, 1992.

BORGES, E.E.L.; VASCONCELOS, P.C.S.; CARVALHO, D.V. et al. Estudos preliminares sobre o efeito do estresse hídrico na germinação de jacarandá-da-Bahia (Dalbergia nigra) e cedro-rosa (Cedrela fissilis). Revista Brasileira Sementes, Brasília, v.13, n.2, p.115-118, 1991.

BRACCINI, A.L.; RUIZ, H.A.; BRACCINI, M.C.L. et al. Germinação e vigor de sementes de soja sob estresse hídrico induzido por soluções de cloreto de sódio, manitol e polietileno glicol. Revista Brasileira Sementes, Brasília, v.18, n.1, p.10-16. 1996.

BRADFORD, K.J. Water relations in seed germination In: KIEGEL, J.; GALILI, S. (Ed) Seed development and germination. New York, Marcel Dekker Inc., 1995. p. 351-396.

BRAGA, R. Plantas do nordeste, Ceará. 4.ed. Natal: UFRN, 1982. 540p. (Coleção mossoroense, 114)

BRASIL. Ministério da Agricultura e Reforma Agrária. Regras para análise de sementes. Brasília: SNDA/DNDV/CLAV, 1992. 365p.

CARPI, S.M.F.; BARBEDO, C.J.; MARCOS FILHO, J. Condicionamento osmótico de sementes de Cedrela fissilis Vell. Revista Brasileira Sementes, Brasília, v.18, n.2, p.271-275, 1996.

CASTRO, E.M.; ALVARENGA, A.A.; ALMEIDA, L.P.et al. Influência do ácido giberélico e do nitrato de potássio na germinação de Guarea guidonia (L.) Sleum. Revista Árvore, Viçosa, v.23, n.2, p.255-258, 1999.

CAVALCANTE, A.M.B.; PEREZ, S.C.J.G.A. Efeitos dos estresses hídrico e salino sobre a germinação de sementes Leucaena leucocephala (Lam) de Wit. Pesquisa Agropecuária Brasileira, Brasília, v.30, n.2, p.281-289. 1995

CHOINSKI, J.S.; TUOHY, J.M. Effect of water potential and temperature on the germination of four species of african savanna trees. Annals of Botany, London, v.68, p.227-233, 1993.

COCHRAN, W.G.; COX, G.M. Experimental design. 2. ed., London: John Wiley \& Sons Inc., 1957. 611p.

DAVIES, P.J. Plant hormones and their role in plant growth and development. New York: Martinus Nijhoof Publisher, 1994. 679p.

DELACHIAVE, M.E.A. Efeito de diferentes potenciais de água sobre alguns aspectos fisiológicos da germinação de Stylosanthes guianensis (Aubl.) Sw. 1984. 85p. Tese (Doutorado em Ecologia e 
Recursos Naturais) - Universidade Federal de São Carlos, São Carlos.

DURAN, J.M.; TORTOSA, M.E. The effect of mechanical and chemical scarification of charlock $S$. arvensis Seed Science \& Technology, Zurich, v.13, p.155-163, 1985.

EIRA, M.T.S. Condicionamento osmótico de sementes de alface (Lactuca sativa L.): efeitos sobre a germinação e desempenho sob estresse hídrico, salino, térmico. 1988. 90p. Dissertação (Mestrado) -Escola Superior de Agricultura Luiz de Queiroz, Piracicaba.

FANTI, S.C.; PEREZ, S.C.J.G.A. Efeitos do estresse hídrico e salino na germinação de Bauhinia forficata Link. Revista Ceres, Viçosa, v. 43, n. 249, p. 654-662, 1996.

. Efeitos do estresse hídrico, salino e térmico no processo germinativo de sementes de Adenanthera pavonina L. Revista Brasileira de Sementes, v. 20, n.1, p.167-177, 1998.

FERREIRA, L.G.R.; REBOUÇAS, M.A.A. Influência da hidratação/desidratação de sementes de algodão na superação dos efeitos da salinidade na germinação. Pesquisa Agropecuária Brasileira, Brasília, v.27, n.4, p.609-615, 1992.

GHASSEMI, F.; JAKEMAN, A.F. \& NIX; M.A. Salinisation of land and water resourses. England: CAB International wallin ford, $1995.381 \mathrm{p}$.

HEYDECKER, W. Stress and seed germination: an agronomic view. In: KHAN, A.A. The physiology and biochemistry of seed dormancy and germination. North-Holland Publishing Company, 1977, p.237282.

JELLER, H.; PEREZ, S.C.J.G.A. Estudo da superação de dormência e da temperatura em sementes de Cassia excelsa SCHRAD. Revista Brasileira de Sementes, Brasília, v.21, n.1, p.32-40, 1999.

_. Efeito da salinidade e da semeadura em diferentes profundidades na viabilidade e no vigor de Copaifera langsdorffii Desf. Revista Brasileira Sementes, Brasília, v.19, n. 2, p. 219-225, 1997.

JOHN, A.Q.; PAUL, T.M. Effect of presowing treatments of Italian cypress (Cupressus sempervirens L.) seed. Advances in Plant Sciences, Kashmir, v.7, n.1, p.191-193, 1994.

KHAN, M.A.; UNGAR, I.A. The role of hormones in regulating the germination of polymorphic seeds and early seedling growth of Atriplex triangularis under saline conditions. Physiologia Plantarum, Copenhagen, v.63, p.109-113, 1985.

KITCHEN, S.G.; MEYER, S.E. Seed germination of intermountain penstemons as influenced by stratification and $\mathrm{GA}_{3}$ treatments. Journal of Enviromental Horticulture, v.9, n.1, p.51-56, 1991.

LABOURIAU, L.G. Seed germination as a thermobiological problem. Radiation and Environmental Biophysics, New York, n.15, p.345-366, 1978.

LABOURIAU, L.G.; VALADARES, M.B. On the germination of seeds of Calotropis procera. Anais da Academia de Ciências, Rio de Janeiro, v.48, p.174-186, 1976.

NASSIF, S.M.L; PEREZ, S.C.J.G.A. Germinação de sementes de amendoim-do-campo (Pterogyne nitens Tul- Fabaceae-mimosoideae) submetidas a diferentes condições de estresse hídrico e salino. Revista Brasileira Sementes, Brasília. v.19, n.2, p.143-150, 1997.

NICOLAS, C., NICOLAS, G., RODRIGUES, D. Antagonistic effects of abscisic acid and gibberellic acid on the breaking of dormancy of Facus sylvatica seeds. Physiologia Plantarum, Copenhagen, v.96, n.2, 
p.244-250. 1996.

PEREZ, S.C.J.G.A.; NASSIF, S.M.L. Prosopis juliflora (S.W.) D.C. (algarobeira): efeitos do envelhecimento, Polietilenoglicol (PEG) e substratos na viabilidade e vigor. Informativo ABRATES, Londrina. v.5, n.2, p.201, 1995.

PEREZ, S.C.J.G. de A.; TAMBELINI, M. Efeito dos estresses salino e hídrico e do envelhecimento precoce na germinação de algarobeira. Pesquisa Agropecuária Brasileira, Brasília, v.30, n.11, p.1289-1295, 1995.

SPIEGEL, M.R. Probabilidade e Estatística. São Paulo: Mc Graw Hill do Brasil, 1978, 518p. (Coleção Shaum)

SALISBURY, F.B.; ROSS, C.W. Plant Physiology. 4.ed. California: Wadsworth Publishing Company, 1992, 682p.

TAMBELINI, M.; PEREZ, S.C.J.G.A. Efeitos do estresse hídrico simulado com PEG(6000) ou manitol na germinação de sementes de barbatimão Stryphnodendron polyphyllum Mart. Revista Brasileira de Sementes, v.20, n.1, p.226-232, 1998.

UNGAR, I.A. Halophyte seed germination. Botany Review, New York, v.44, p.233-264, 1978

VERTUCCI, C.W. The effects of low water contents on physiological activities of seeds. Physiologia Plantarum, Copenhagen, v.77, p.172-176, 1989.

VILLELA, F.A.; D. FILHO, L.; SEQUEIRA, E.L. Tabela de potencial osmótico em função da concentração de polietilenoglicol 6000 e da temperatura. Pesquisa Agropecuária Brasileira, Brasília, v.26, n.11/12, p.1957-1968, 1991.

WILLIAN, M.D.; UNGAR, I.A. The effect of environmental parameters on the germination, growth and development of Suaeda depressa (Prush) Wats. American Journal of Botany, Columbus, v.59, p.912918, 1972.

ZPEVAK, F.A.; Efeitos do ácido abscísico, potencial hídrico, temperatura e tratamentos para quebra de dormência na germinação de sementes de Dimorphandra mollis Benth. 1994. 104p. Dissertação (Mestrado em Ecologia e Recursos Naturais) - Universidade Federal de São Carlos, São Carlos. 